\title{
SIFCON'S Behaviour on Partial Replacement of Cement with Waste Glass Powder
}

\author{
Priyanka Tiwari, Yogendra Kushwaha, Akash Agrawal
}

\begin{abstract}
The main objective of this work is to study the behaviour of SIFCON produced by partial replacement of cement with glass powder. Slurry Infiltrated Fibrous Concrete (SIFCON) is a special type of fibre reinforced concrete (FRC) which have large amount of fibre. FRC contain fibre only $2 \%$ to $5 \%$ by volume of cube because of balling and clustering problem but in SIFCON we can use fibre from 5 to $20 \%$ of volume of cube.

Waste glass contain high silica ( $\mathrm{SiO} 2)$ due to which when these waste glass is ground to very fine powder react with alkalies in cement and form cementitious product that help in strength contribution. Further in this research work we are going to use $6 \%, 12 \%$ and $18 \%$ of steel fibre by volume of $150 \mathrm{~mm} \times 150 \mathrm{~mm} \times 150 \mathrm{~mm}$ cube to find out the optimum strength and compare it with the strength of SIFCON produced by partial replacement of cement with glass powder at the days of 7days, 14days \&28 days. This research therefore is a study of the performance of the SIFCON concrete made of $6 \%, 12 \% \& 18 \%$ of steel fibre from which optimum fibre content was obtained and then by using this volume of fiber, behaviour of SIFCON produced by partial replacement of cement with glass powder were studied. In this work $5 \%, 10 \%, 15 \%, 20 \%$ and $20 \%$ Glass powder is replaced by weight of cement.

Based on this study compressive strength versus percentage of replacement of Glass powder curves have been plotted.
\end{abstract}

Index Terms - fibre reinforced concrete, Glass Powder, replacement of cement, SIFCON.

\section{INTRODUCTION}

SIFCON is a modern material in construction which is costly, very few have knowledge about SIFCON behaviour is known. The objectives of this experimental study are to obtain the information about compressive and flexural

Manuscript revised on October 15, 2019 and published on October 28, 2019

Priyanka Tiwari, PG Student Department of Civil Engineering, Sam Higginbottom University of Agriculture, Technology \& Sciences, Prayagraj, Uttar Pradesh, India.

Yogendra Kushwaha, Assistant Professor, Department of Civil Engineering, Sam Higginbottom University of Agriculture, Technology \& Sciences, Prayagraj, Uttar Pradesh, India.

Akash Agrawal, Assistant Professor, Department of Civil Engineering, Sam Higginbottom University of Agriculture, Technology \& Sciences, Prayagraj, Uttar Pradesh, India. strength behaviour of SIFCON. Further the objective of this study is to replace the cement with glass powder in various proportions in SIFCON so that the effect of glass powder on SIFCON can be determined. Hence in this way the cost of construction of SIFCON can be reduced.

The scope of this experimental study was designed in such manner that it fulfils the objectives as planned. It involved conducting a number of tests related to compressive and flexural strength behaviour of SIFCON; the following parameters were studied for every one of these tests:

a) Studying the effect of glass powder which is partly replaced by cement in SIFCON with most desirable fibre content. Four different fractions were used, 5\%, 10\%, 15\%, and $20 \%$.

b) Studying the effects at different fraction of volume of steel fibres, and to determine the required fibre content. Three different fractions of volume were used, $6 \%, 12 \%$ and $18 \%$.

For each and every experiments and investigation, SIFCON specimens were compared to each other as well as the results were compared to control conventional concrete specimens of M-30 grade concrete which is designed as a control mix.

The concrete properties are affected by multiple factors such as,coarse aggregate, properties of cement, fine aggregate. Other than this, the fibre reinforced concrete is affected by following factors:

1) Fibre type

2) Fibre quantity

3) Aspect ratio

4) Fibre orientation

\section{Glass Powder}

Glass is a hard brittle, non-crystalline more or less transparent substance produced by fusion, usually consisting of mutually dissolved silica and silicate that also contain soda and lime. Glass can be considered as an environmentally friendly material because it can be recycled several times and can be used in many applications. According to estimation several million tonne of waste glass are generated worldwide annually. Waste glass is generated mainly from waste containers, door and window glasses, bulbs, tube light, windshield, liquor bottles etc (Bhupendra Singh Shekhawat and Dr. Vanita Aggarwal, "Utilisation of Waste Glass Powder in Concrete- A Literature Review). Everywhere, storage and safe disposal of waste glass creates major problem for municipalities and to reduce this problem waste glass is recycled. Glass is recycled by melting a mixture containing material such as soda ash, silica, calcium 
International Journal of Research in Advent Technology, Vol.7, No.9, September 2019

E-ISSN: 2321-9637

Available online at www.ijrat.org

carbonate and recycled glass piece. This blend is then heated to very high temperature where they melt followed by a rapid cooling process that effectively creates the crystallization glass it is often associated with. After the production the glass is used as a set of new glass.

\section{Fibre Mechanism}

Fibre work with concrete utilizing two mechanisms:

I. Spacing mechanism

II. Crack bridging mechanism

The spacing mechanism requires a large number of fibres well distributed within the concrete matrix to arrest any existing micro crack that could potentially expand create a sound crack. For typical volume of fractions of fibres utilizing small diameter of fibres or micro fibres can ensure the required no of fibres for micro crack arrest.

The second mechanism termed crack bridging requires larger straight fibres with adequate bond to concrete. Steel fibres are considered a prime example of this fibre type that is commonly referred as large diameter fibres or micro fibres.

\section{Methodology}

The research methodology was to conduct a literature review of the studies on slurry infiltrated fibrous concrete and concrete produced by partial replacement of glass powder with cement that have been conducted in the past two decades. On the basis of the literature review, knowledge gaps were identified. It was realized that mechanical properties of slurry infiltrated fibrous concrete have been studied by many researchers in different areas of world. An experimental program was developed to study the properties of slurry infiltrated fibrous concrete in fresh and hardened state. The experimental program included number of test such that compressive strength and Flexural Strength at different amount of fibre and at different test age such that at 7 day, 14 day and 28 days. Concrete mixture proportions for control concrete of M-30 grade were developed to maintain a target slump (Antonio Nanni, "PROPERTIES OF ARAMID-FIBRE REINFORCED CONCRETE AND SIFCON",). Using different percentage of steel fibres, test specimens were cast, cured and tested as per the experimental matrix. The results of the plain concrete, slurry infiltrated fibrous concrete and slurry infiltrated fibrous concrete produced by partial replacement of cement with glass powder were compared to quantify the beneficial effects of SIFCON

\section{LITERATURE REVIEW}

SIFCON was first developed in 1979 by Lankard Materials Laboratory, Columbus, Ohio, USA, by incorporating large amounts of steel fibres in steel fibre reinforced cement-based composites.

This represents a literature review on compressive and flexural behaviour of SIFCON and effect of partial replacement of cement by glass powder on the properties of SIFCON. Several experimental investigations had been conducted in order to increase strength of concrete using various admixtures. Latest was Halit Yazici [2016] proposed an experimental study on Improvement on SIFCON Performance by Fibre Orientation and High-Volume Mineral Admixtures. In this investigation the effects of high-volume mineral admixture replacement (Class $\mathrm{C}$ fly ash and ground granulated blast furnace slag (GGBS)) and steel fiber alignment, on the mechanical properties of SIFCON have been investigated. Fly ash or GGBS with $50 \%$ (by weight) in slurry was replaced with cement and two different steel fiber alignments (random and oriented in one direction) were taken in this study.

Test result indicated that when fly ash was replaced with cement than viscosity of slurry increases considerably. On the other hand, GGBS did not change the viscosity remarkably. However, viscosity can be controlled by using super plasticizer. Hence cement content of SIFCON can be reduced up to $50 \%$.

\section{MATERIALS \& METHODOLOGY}

\section{Water}

For concreting operations, water is very important \& almost free available. Generally, cement requires about three-tenth of water for the hydration although some additional water is also required to lubricate the mix. The water used for curing and mixing should be free from impurities.

Water to be used in the concrete work should have following properties:

i. The water should be free from the deleterious amount of acids, salts, alkalis or any other organic or inorganic impurities.

ii. The water should not contain injurious amount of soils.

iii. It should be free from any contaminating substances, which can cause adverse effect on concrete or to reinforcement.

iv. The water which can be used for the drinking purposes.

The function of water in concrete

i. It is mainly required for the hydration of cement.

ii. It forms a binding matrix in which the aggregates are held in suspension till the mixture has hardened.

iii. It is also required to lubricate the mixture, to make the mix workable.

\section{Portland cement}

The Portland cement is very fine material having cohesive $\&$ adhesive properties, which provide a medium to bind the discrete ingredients. It is a homogeneous mixture of materials mainly containing lime $(\mathrm{CaO})$ and silica $(\mathrm{SiO} 2)$ with a smaller proportion of iron oxide $(\mathrm{Fe} 2 \mathrm{O} 2)$ and Alumina (Al2O3)( Dr. G. Vijayakumar, H. Vishaliny and Dr. D. Govindarajulu, "Studies on Glass Powder as Partial Replacement of Cement in Concrete Production). On the basis of 28 days test as per IS4031-1948 the Ordinary Portland Cement was categorized into three categories, i.e. 53 grade, 43 grade and 33 grade

\section{Steel fibre}

Low tensile strength steel fibre of diameter $1 \mathrm{~mm}$ is used in this study. For this purpose locally available binding wire is 
used. Length of the fibre is taken as $50 \mathrm{~mm}$. The steel fibre as binding wire; was purchased from Prayagraj market.

$\begin{array}{lc}\text { Properties of Fibre Supplied By Manufacturer } \\ \text { Carbon } & 0.06 \\ \text { Manganese } & 0.39 \\ \text { Sulphur } & 0.23 \\ \text { Phosphorous } & 0.022 \\ \text { Silicon } & 0.19 \\ \text { Aluminum } & 0.022 \\ \text { Carbon equivalent } & 0.13 \\ \text { Yield strength N/mm } 2 & 331 \\ \text { UTS N/mm2 } & 410\end{array}$

The type of fibre used in this study was made of steel and having unit weight of $7850 \mathrm{~kg} / \mathrm{m}^{3}$. Low tensile strength steel fibre of diameter $1 \mathrm{~mm}$ is used in this study. Steel fibres of aspect ratio of 50 were cut into required length of $50 \mathrm{~mm}$. The ultimate tensile strength was $410 \mathrm{MPa}$. Black steel fibres are commercially available and are generally used for binding the steel reinforcement in RCC works

\section{. Fine Aggregates}

Sand conforming to grading zone II as per the specifications of IS 383:1970 is used. The sand was kept in air to dry out and sieved to eliminate the foreign substances before mixing.

The bulk density, fineness modulus, specific gravity and water absorption were determined.

\section{Glass powder}

The waste glass contain high silica ( $\mathrm{SiO} 2)$ due to which when these waste glass is ground to very fine powder; it reacts with alkalis present in the cement and form cementitious product that helps in the contribution of strength. In this study very fine glass powder is used.

\section{Chemical composition of Glass Powder}

S. No. Chemical Compound Percentage by Mass

$\begin{array}{lll}1 \mathrm{SiO}_{2} & 67.33 \\ 2 \mathrm{Fe}_{2} \mathrm{O}_{3} & 1.42 \\ 3 \mathrm{Al}_{2} \mathrm{O}_{3} & 2.62 \\ 4 \mathrm{CaO} & 12.45 \\ 5 \mathrm{Na}_{2} \mathrm{O} & 12.05 \\ 6 \mathrm{MgO} & 2.74 \\ 7 \mathrm{~K}_{2} \mathrm{O} & 0.638 \\ 8 \mathrm{SrO} & 0.016 \\ 9 \mathrm{ZnO} & 0.008 \\ 10 \mathrm{P}_{2} \mathrm{O}_{5} & 0.05 \\ 11 \mathrm{CuO} & 0.009 \\ 12 \mathrm{NiO} & 0.014 \\ 13 \mathrm{Cr}_{2} \mathrm{O}_{3} & 0.022 \\ 14 \mathrm{ZrO}_{2} & 0.019 \\ 15 \mathrm{TiO}_{2} & 0.157\end{array}$

Experimental Set-Up and Procedure:

A series of cube and prism specimens were tested in the laboratory to investigate the compressive strength and flexural strength respectively. The preparatory work and the procedure of the experiments had described. The variables of the experimental specimens were the partial replacement of cement by glass powder. The process of experiment shows the variation in the parameter of strength with variation in the amount of glass powder and steel fibre.

The experimental results are presented including the failure loads and the failure types and the influence of partial replacement of cement by glass powder.

The experimental setup includes following steps

\section{Selection of Mould}

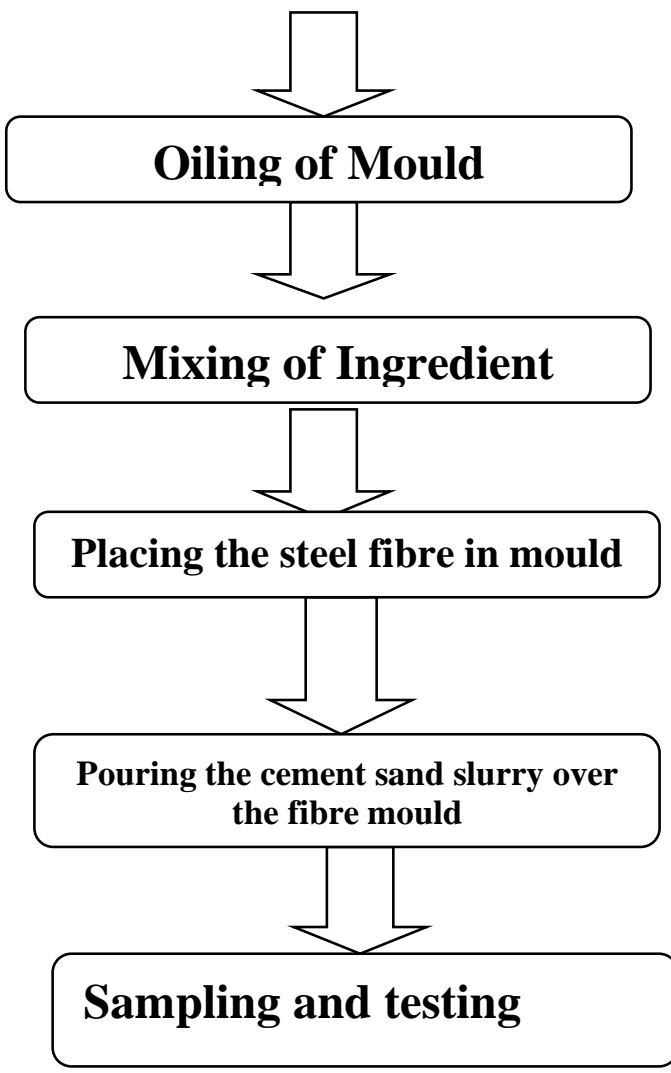

The experimental setup

\section{RESULT \& DISCUSSION}

\section{A. Flexural strength of SIFCON}

To measure the flexural strength of SIFCON, three-point load method was used.

The flexural strength of the prisms was computed by following equation

Modulus of rupture, $\mathrm{F}_{\mathrm{b}}=\mathrm{PL} / \mathrm{bd}^{2}$

Where $\mathrm{P}=$ Maximum applied load in $\mathrm{N}$

$\mathrm{b}=$ Specimen width in $\mathrm{mm}$

$\mathrm{L}=$ Specimen supported length in $\mathrm{mm}$

$\mathrm{d}=$ Measured specimen depth at the failure point, $\mathrm{mm}$ 


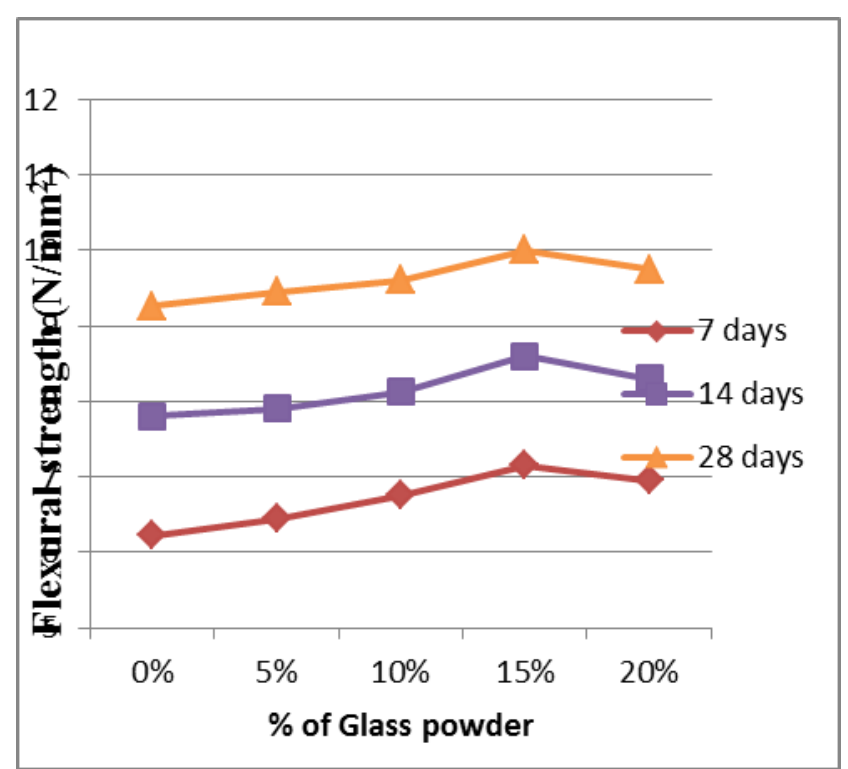

Flexural strength of SIFCON with glass powder after 7, 14 and 28 days

\section{B. Compressive Strength Test}

Compressive strength can be determined by using following formula:

Compressive Strength $=\mathrm{P} / \mathrm{A}$

Where $\mathrm{P}=$ load and $\mathrm{A}=$ area of cube.

Compressive strength at various percentage of steel fibre at 7, 14 and 28 days are given below:

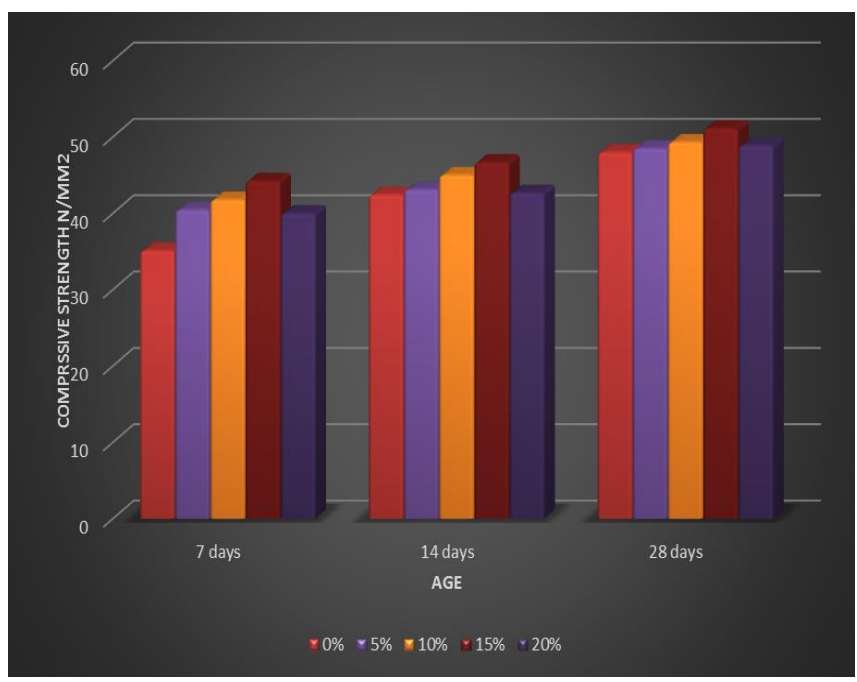

Compressive strength of SIFCON with glass powder

\section{CONCLUSIONS}

In case of addition both steel fibres and glass powder, $12 \%$ of steel fibre and $15 \%$ replacement of glass powder with cement can be taken as the optimum amount for compressive strength as well as flexural strength which provides maximum possible compressive strength and flexural strength at any age for SIFCON produced by partial replacement of glass powder with cement.
From the test result we can conclude that

1) When the addition of low tensile strength steel fibre, $12 \%$ fibre volume is taken as the optimum amount for compressive strength, which provides maximum possible compressive strength at any age for SIFCON with steel fibres. Hence $12 \%$ volume of steel fibres can be considered as optimum volume of steel fibres for compression.

2) In case of addition both steel fibres and glass powder, $12 \%$ of steel fibre and $15 \%$ replacement of glass powder with cement can be taken as the optimum amount for compressive strength, which provides maximum possible compressive strength at any age for SIFCON produced by partial replacement ofglass powder with cement.

3) In case of addition low tensile strength steel fibre, $12 \%$ fibre volume can be taken as the optimum dosage for flexural strength, which can be used for giving maximum possible flexural strength at any age for SIFCON with steel fibres. Hence $12 \%$ volume of steel fibres can be considered as optimum volume of steel fibres for flexural strength of SIFCON.

4) In case of addition both steel fibres and glass powder, $12 \%$ of steel fibre and $15 \%$ replacement of glass powder with cement can be taken as the optimum amount for flexural strength, which provides maximum possible flexural strength at any age for SIFCON produced by partial replacement of glass powder with cement.

5) In case of addition of steel fibre in SIFCON, the maximum percentage increase of compressive strength of SIFCON compared with compressive strength of control mix is observed from $25.42 \%$ at 7 days. The maximum percentage increase of compressive strength of SIFCON compared with compressive strength of control mix is observed from $36.90 \%$ at 14 days. The maximum percentage increase of compressive strength of SIFCON compared with compressive strength of control mix is observed from $23.07 \%$ at 28 days.

6) In case of addition of glass powder and steel fibre both, the maximum percentage increase of compressive strength of SIFCON with glass powder compared withcompressive strength of SIFCON with $12 \%$ of steel fibres is observed as $9.96 \%$ at 14 days. The maximum percentage increase of compressive strength of SIFCON with glass powder compared withcompressive strength of SIFCON with $12 \%$ of steel fibres is observed as $6.47 \%$ at 28 days.

7) In case of addition of steel fibre, the maximum percentage increase of flexural strength of SIFCON compared with flexural strength of control mix is observed as $65.77 \%$ at 7 days. The maximum percentage increase of flexural strength of SIFCON compared with flexural strength of control mix is observed as $92.59 \%$ at 14 days. The maximum percentage increase of flexural strength of SIFCON compared with flexural strength of control mix is observed as $109.75 \%$ at 28 days.

8) In case of addition of glass powder and steel fibre both, the maximum percentage increase of flexural strength of SIFCON with glass powder compared withcompressive strength of SIFCON with $12 \%$ of steel fibres is observed as $14.51 \%$ at 7 days. The maximum percentage increase of 


\section{Available online at www.ijrat.org}

flexural strength of SIFCON with glass powder compared with flexural strength of SIFCON with $12 \%$ of steel fibres is observed as $8.97 \%$ at 14days. The maximum percentage increase of flexural strength of SIFCON with glass powder compared with compressive strength of SIFCON with $12 \%$ of steel fibres is observed as $8.10 \%$ at 28 days

\section{REFERENCES}

[1] Antonio Nanni, "PROPERTIES OF ARAMID-FIBRE REINFORCED CONCRETE AND SIFCON", J. Mater. Civ. Eng. 1992.4:1-15.

[2] Ahmad Shayanand Aimin Xu, "Performance of glass powder as a pozzolanic material in concrete: A field trial on concrete slabs", Cement and Concrete Research 36 (2006) 457-468.

[3] Arun Aniyan Thomas, "STRENGTH And Behaviour OF SIFCON with different types of fibres", International Journal of Civil Engineering and Technology (IJCIET, Volume 5, Issue 12, December (2014), pp. 25-30.

[4] Bhandari P.S., Dhale S.A., Ghutke V.S. and Pathan V.G, "Influence of Fine Glass Aggregate On Cement Mortar", International Journal Of Engineering And Computer Science ISSN:2319-7242 Volume 3 Issue 1, January 2014 Page No. 3607-3610.

[5] Bhat et al [1994] proposed that partial replacement of glass powder with cement in concrete increases the compressive strength of concrete.

[6] Bhupendra Singh Shekhawat and Dr. Vanita Aggarwal, "Utilisation of Waste Glass Powder in Concrete- A Literature Review", International

\section{AUTHORS PROFILE}

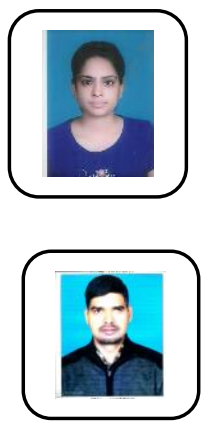

Priyanka Tiwari, B.Tech (AKTU) M.tech Student, Department of Civil Engineering, VIAET, SHUATS, Prayagraj (Allahabad), India

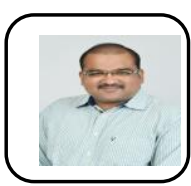

Er. Yogendra Kushwaha B.Tech Civil, M.Tech Assistant Professor, Department of Civil Engineering,VIAET, SHUATS, Prayagraj (Allahabad), India

Er. Akash Agrawal, B.Tech Civil, M.Tech Construction Management and MBA (HR), Assistant Professor, Department of Civil Engineering, VIAET, SHUATS, Prayagraj (Allahabad), India.
Journal of Innovative Research in Science, Engineering and Technology Vol. 3, Issue 7, July 2014.

[7] Bhosale et al [2005] investigated the green concrete which was produced by using waste glass powder

[8] Caglar Yalçinkaya, Ahsanollah Beglarigale and Halit Yazici, "The effect of metakaolin and end type of steel fibre on fibre SIFCON matrix bond characteristics",Usak University Journal of Material Sciences 1 (2014) $97-105$

[9] Dr. H. K. Sharma and V.P. Singh, "PERFORMANCE CHARACTERISTICS SIFCON PLATES", WSEAS International Conference on GEOLOGY and SE [20]

[10] Dr. G. Vijayakumar, H. Vishaliny and Dr. D. Govindarajulu, "Studies on Glass Powder as Partial Replacement of Cement in Concrete Production", International Journal of Emerging Technology and Advanced Engineering, Volume 3, Issue 2, February 2013.

[11] Halit Yazici, "Improvement on SIFCON Performance by Fibre Orientation and High Volume Mineral Admixtures", JOURNAL OF MATERIALS IN CIVIL ENGINEERING ASCE / NOVEMBER 2010 / 1093 